Bond University

Research Repository

\title{
Tracking Training Load and Its Implementation in Tactical Populations: A Narrative Review
}

Maupin, Daniel; Schram, Ben; Orr, Rob Marc

Published in:

Strength and Conditioning Journal

DOI:

10.1519/SSC.0000000000000492

Licence:

Other

Link to output in Bond University research repository.

Recommended citation(APA):

Maupin, D., Schram, B., \& Orr, R. M. (2019). Tracking Training Load and Its Implementation in Tactical Populations: A Narrative Review. Strength and Conditioning Journal, 41(6), 1-11.

https://doi.org/10.1519/SSC.0000000000000492

\section{General rights}

Copyright and moral rights for the publications made accessible in the public portal are retained by the authors and/or other copyright owners and it is a condition of accessing publications that users recognise and abide by the legal requirements associated with these rights.

For more information, or if you believe that this document breaches copyright, please contact the Bond University research repository coordinator. 
Tracking Training Load and Its Implementation in Tactical Populations: A Narrative Review

Danny Maupin D. Phty., ATC

PhD Student, Faculty of Health Sciences and Medicine Bond University

Bond Institute of Health and Sport, Bond University, Gold Coast, QLD, Australia 4216

daniel.maupin@student.bond.edu.au

2 Promethean Way Robina, QLD 4226

Phone: (07) 55951111

Fax: (07) 55953524



Dr. Ben Schram PhD., D. Phty.

Assistant Professor, Faculty of Health Sciences and Medicine Bond University

Tactical Research Unit, Bond University, Gold Coast, QLD, Australia, 4216

bschram@bond.edu.au

2 Promethean Way Robina, QLD 4226

Phone: (07) 55951111

Fax: (07) 55953524

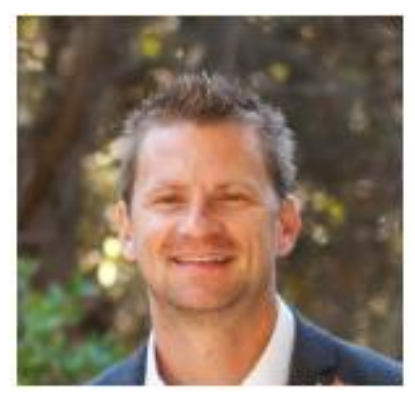


Dr. Robin Orr PhD.

Associate Professor, Faculty of Health Sciences and Medicine Bond Univeristy

Tactical Research Unit, Bond University, Gold Coast, QLD, Australia, 4216

rorr@bond.edu.au

2 Promethean Way Robina, QLD 4226

Phone: (07) 55951111

Fax: (07) 55953524

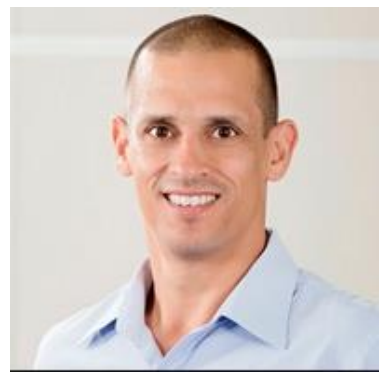

Danny Maupin is a PhD Student in the Faculty of Health Sciences and Medicine at Bond University.

Ben Schram is an Assistant Professor in the Faculty of Health Sciences and Medicine at Bond University. Robin Orr is an Associate Professor in the Faculty of Health Sciences and Medicine at Bond University.

Key Words: Police, Military, Firefighters, Injury Prevention, Overload

Abstract: Tactical populations often participate in demanding physical training and perform strenuous workplace tasks, increasing injury risk. Mitigating injury risk is vital for maintaining trained personnel and should be a focus for tactical populations. One such method, tracking training load, has not been studied in-depth in tactical populations, despite documented effectiveness in elite sport. Most injuries to tactical personnel are overuse in nature and therefore may be prevented by optimizing training load. 
While the methods used in elite sport may not be directly transferrable to tactical environments, they may be used to inform injury mitigation strategies in tactical populations.

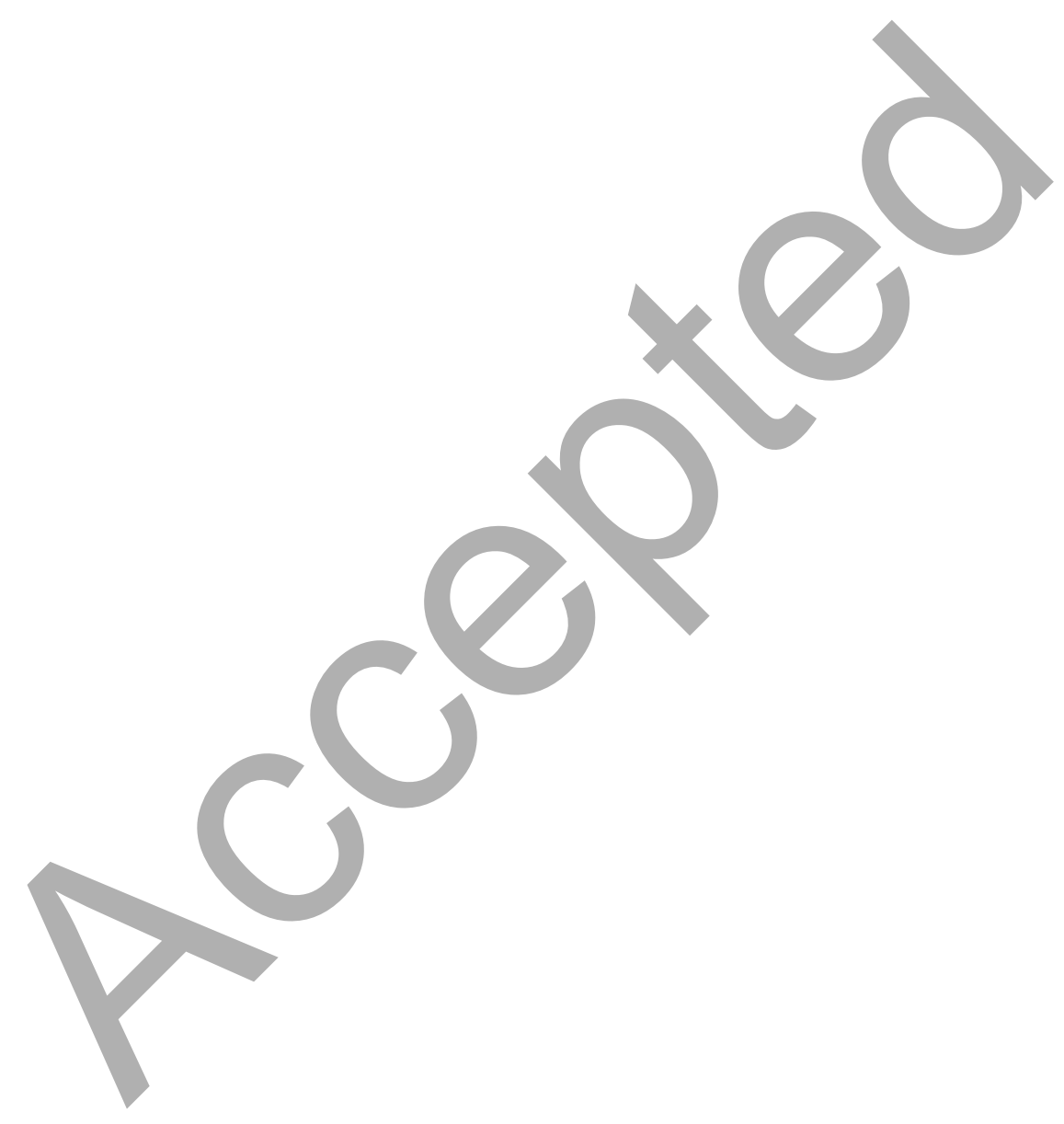


1

2

3

\section{Tracking Training Load and Its Implementation in Tactical Populations: A Narrative Review}

2

3 Key Words: Police, Military, Firefighters, Injury Prevention, Overload

4

5 Abstract: Tactical populations often participate in demanding physical training and perform strenuous

6 workplace tasks, increasing injury risk. Mitigating injury risk is vital for maintaining trained personnel

7 and should be a focus for tactical populations. One such method, tracking training load, has not been

8 studied in-depth in tactical populations, despite documented effectiveness in elite sport. Most injuries

9 to tactical personnel are overuse in nature and therefore may be prevented by optimizing training load.

10 While the methods used in elite sport may not be directly transferrable to tactical environments, they

11 may be used to inform injury mitigation strategies in tactical populations.

3

4

5

6

17

8

9

0

1

2


Introduction

24 Tactical populations are inclusive of, but not limited to, firefighters, police officers, and military

25 personnel. Despite intermittent sedentary occupational tasks, especially police, (e.g. sitting in a patrol

$\left.26 \operatorname{car}^{1}\right)$, tactical populations are required to perform tasks in stressful, and physically demanding

27 situations ${ }^{1}$. This requirement often occurs while these personnel are carrying external loads, such as

28 body armor and other personnel protection equipment ${ }^{2}$. Externals loads often vary and can range from

$2910 \mathrm{~kg}$ in general police units ${ }^{2}$, to $22 \mathrm{~kg}$ in firefighters ${ }^{3}$, while military personnel can carry average loads of $3045 \mathrm{~kg}^{4}$. The addition of these loads not only causes an increase in metabolic demand ${ }^{5}$, but can also lead

31 to an increased risk of injury ${ }^{6}$. In police in particular, these loads further increase upon admission to

32 specialist units 7,8 . Specialist police units, due to the requirement to carry additional equipment, such as 33 riot shields and more substantial body armor, can be required to carry loads ranging from around $20 \mathrm{~kg}^{9}$ 34 to $40 \mathrm{~kg}^{10}$, which can cause even greater metabolic demands and higher risk of injury ${ }^{6,11}$.

While each tactical population undergoes high physical stress that increases the risk of injury, the

37 stresses placed on each of these tactical populations vary. Firefighters are typically faced with significant 38 environmental hazards ${ }^{12}$, military personnel are more likely to carry considerably heavier loads ${ }^{13}$, and 39 police officers are more likely to encounter resistant and uncooperative suspects ${ }^{14}$. Furthermore, and 40 apart from the nature of the occupation itself, sport and physical training can be a leading source of 41 injury in tactical populations ${ }^{15}$. However, sport and physical conditioning are integral to many tactical 42 populations, with appropriate physical training required to increase occupational capability either 43 directly (increased task performance) or indirectly (improved general health) ${ }^{2,16}$. 
Given the high injury risk of tactical populations ${ }^{6}$, it is vital that injury mitigation strategies are

researched. One such strategy that has not been explored in depth is the monitoring and optimization of

47 training load (TL), despite documented effectiveness in elite sport ${ }^{17}$. The purpose of this narrative

review is to explore the potential benefits and limitations of tracking $T L$ in tactical populations with the

49 intent of reducing injury risk while maintaining or increasing fitness. This review will summarize

50 information regarding injuries in tactical populations, and the potential usefulness of optimizing training

51 loads. Information regarding training load, how it can be measured, as well as previous research

52 examining the relationship between training load and injuries, fitness, and performance will also be

53 presented.

\section{Injuries in Tactical Populations}

55 With differing occupational and physical training demands, the location and incidence of injuries

56 experienced can vary; however, injury types are known to be similar across these populations ${ }^{18}$. In a

57 study by Taylor et al. ${ }^{19}$ it was found that firefighters suffered injuries at a rate of 177 per 1000 full-time

58 employees per annum. Firefighters were most likely to suffer joint sprains and muscle strains,

59 accounting for $66.5 \%$ of all injuries, followed by contusion/crush injuries, mental disorders, and open

60 wounds. The most common sites of injury being the knee, lower back, shoulder and ankle ${ }^{19}$.

61 In law enforcement, a critical review ${ }^{18}$ found injury rates ranging from 240 to 2500 per 1000 personnel

62 per annum, with multiple articles reviewed reporting the most common region of injury being the upper

63 extremity (32.95\% to $43.42 \%$ of injuries), while another stated the most common site was Other

64 Unspecified sites (63.41\%), followed by torso and back (20.49\%). This review found the most common

65 injury type to be sprains and strains ( $42.36 \%$ to 94.59\%), followed by Other Muscle pains and Other

66 Natures of injury ${ }^{18}$. 
67 With regards to military, incidence rates have been reported to range from 23 incidents, for active duty

68 personnel, to 34 incidents, for reserve personnel, per 100 person-years of active service, with "minor

69 personal injury" being the most common for both groups ${ }^{20}$. Their injuries were found to most

70 commonly be overuse or stress syndrome, muscle strains, ankle sprains, and stress fractures which

71 typically occurred at or below the knee ${ }^{21}$.

72 Injuries in these populations can have serious downstream effects, such as a temporary or permanent 73 loss of experience and skills, or even worse, higher workforce strain due to the requirement of covering 74 injured personnel ${ }^{22,23}$. Injuries to tactical populations can also result in high monetary costs to treat and, 75 if needed, replace (e.g. temporarily or permanently) injured personnel, placing an increased financial 76 burden on the organization ${ }^{22,23}$. For example, the financial cost for medical care and salaries of soldiers 77 in the United States (U.S) Army is estimated to be about $\$ 1.5$ billion (USD) per year ${ }^{23}$. By exploring 78 causative factors for these injuries, and implementing programs to reduce these injuries, some of these 79 negative effects may be mitigated.

80 Numerous causative factors have been studied in tactical populations, such as poor metabolic fitness 81 levels ${ }^{24}$, high body mass index (BMI) ${ }^{25}$, history of previous injury ${ }^{26}$, and smoking ${ }^{27}$. In 2000 , Kaufman et 82 al. ${ }^{21}$ discussed how training load (TL) could potentially be another causative factor, and how optimizing 83 TL may decrease injury risk while promoting fitness in a military population. Previous research has 84 shown that an excessive increase in physical activity is linked with an increased injury risk ${ }^{26,28}$. In a study 85 by Trank et al. ${ }^{28}$, it was found that U.S. Navy Recruits who completed the highest running mileage (>25 86 miles $(40.23 \mathrm{~km})$ ) also had a significantly higher risk of injury, with no significant change in 1.5 mile (2.41 $87 \mathrm{~km}$ ) run performance. While the need to track TL is evident, a cursory search of the literature shows that 88 little research has been performed to date with regards to quantifying TL in tactical populations. In fact, 89 a systematic review found only two articles regarding TL tactical populations, but these articles focused 90 mainly on increases in physical activity ${ }^{29}$. Despite minimal information pertaining to the tactical 
91 environment, it has become a popular tool in elite sporting teams. Similar to the study by Trank et al. ${ }^{28}$,

92 a medium effect size ( $r=0.59 ; \mathrm{Cl}$ and $p$ not reported) was found between higher running distances

93 during a given month in endurance runners and number of injury days the following month ${ }^{30}$. By

94 implementing methods that track TL, sporting teams are able to adjust training stimuli at an individual 95 level, and on a weekly basis to reduce injury risk and also increase performance ${ }^{17}$. Given the significant 96 costs associated with injuries, and the increased risk of injury in tactical populations caused by higher 97 physical loads, a means of monitoring TL and their associated effects on injury risk could prove beneficial 98 for tactical populations ${ }^{26,28}$.

\section{Training Load}

101 The International Olympic Committee consensus statement defines TL as a cumulative amount of stress 102 on an individual from single, or multiple, training sessions over time ${ }^{31}$. TL is typically measured using 103 either external methods (e.g. total distance run, or speed) or internal methods (e.g. heart rate or rating 104 of perceived exertion) ${ }^{17}$. External load (EL) has previously been defined as "any external stimulus 105 applied to the athlete that is measured independently of their internal characteristics", while internal 106 load (IL) is "load measurable by assessing internal response factors within the biological system, which 107 may be physiological, psychological, or other" ${ }^{31}$. Tracking EL can communicate the total amount of work 108 completed, while information yielded from IL typically conveys how the individual is adapting 109 physiologically ${ }^{31}$. Emphasis is placed upon the importance of utilizing both measures, as together they 110 provide a more comprehensive view of the physical stress an individual is experiencing ${ }^{17}$. For example, 111 an individual may perform the same overall output (as measured by EL, such as distance) on two 112 different days, however their ability to respond to this output (as measured by IL, such as heart rate) 113 may have changed. Potential differences between responses to training may provide insights as to 
whether the individual is in a state of 'readiness' and able to tolerate high TL or 'fatigue' and potentially at an increased risk of both injury and decreased performance ${ }^{32}$.

Rapid changes in both EL and IL have previously been linked to higher risk of injury in the literature ${ }^{17}$. 118 One example shows $40 \%$ of injuries were the result of a rapid change in TL in the preceding week in 119 Australian football ${ }^{33}$. Factors further compounding the issue were proposed by Gabbett that athletes

External Measurements of Training Load

127 EL is measured in an attempt to define the total work completed ${ }^{31}$. EL measurements can include who over-train or under-train are at higher injury risks ${ }^{17}$. These issues have led to the development of monitoring both IL and EL over the short-term (acute, typically 1 week) and long-term (chronic, 3-6 weeks) periods, and weekly changes to track overall and rapid changes in workload ${ }^{17}$. There are various methods of measuring TL reported in the literature, each of which have benefits and limitations; the following sections will explore these various methods.

distance run, tracking volume-load during strength training sessions, and number of sprints completed, among others ${ }^{17}$. Measuring EL has been aided with the advent of Global Positioning System (GPS) devices and the subsequent accessibility of these relatively low cost devices, which allow for accurate measurement of the above variables ${ }^{34}$. The use of GPS to measure EL is common practice in many professional sports including Australian Football League (AFL), rugby league, and soccer ${ }^{34}$. Research has shown the effectiveness and validity of GPS to measure EL in these sports ${ }^{35,36}$. However, there are concerns of the precision of GPS with regards to high rates of change in velocity and while GPS technology has seen an increase in data accuracy, there are still some limitations in regards to very high speed running $(>20 \mathrm{~km} / \mathrm{hr})^{37}$. While there may be potential validity issues at high speed, has been estimated that the speed of military marches while on level ground is $5.3 \mathrm{~km} / \mathrm{h}^{38}$, which may allow GPS 
devices to accurately record data. Practitioners and clinicians may be able to utilize these devices effectively during training stations and while personnel are on duty and be able to record distance covered.

141 Another concern with GPS units is the high cost associated with them ${ }^{39}$. Research has shown that 142 utilizing GPS on a cellular phone may provide an alternate way to measure distance, as the accuracy 143 between the two was comparable with an approximately $3 \%$ variation identified when measuring 144 distance and average speed ${ }^{40}$. Of importance, this study compared the cellular device to GPS devices 145 with lower sampling rates and more limited accuracy, therefore more variation may exist when 146 comparing cellular devices to GPS devices with higher sampling rates ${ }^{40}$. Utilizing cellular phones or 147 fitness watches may be an alternative tool for tactical practitioners to pursue if the acquisition of GPS 148 units proves too costly. One key area of difference between tactical populations and athletics may be 149 potential security concerns and GPS units. Recently data collected by a wearable GPS unit showed the

location of a secure U.S. military facility as discussed in an article published by Liz Sly in the Washington Post on January $29^{\text {th }}, 2018$. Tactical personnel will need to ensure that the devices they are using are secure and will not lead to similar issues.

Apart from GPS devices to track EL, there are other, more cost-effective methods. One such method is utilizing volume-load per the NSCA's definition (number of repetitions $x$ external load [kg]), a convenient method as it does not require any additional equipment ${ }^{41}$. Whereas repetition-volume is the total number of repetitions performed during a workout, volume-load also incorporates the weight lifted and is likely better at quantifying the total amount of work completed ${ }^{41}$. For example, if a police officer completes 4 sets of 12 repetitions of bench press at $100 \mathrm{~kg}$, their volume load will be 4800 "work units", while their repletion-volume will be 48 . Volume-load can be used during physical training sessions, when tactical personnel are participating in strength training, to track and adjust based on previous and future loads. More complex methods have that determine mechanical work during resistance exercises may be 
utilized during strength sessions; however these require additional devices, such as force places, accelerometers, and inertial sensors ${ }^{39}$. While these devices have been shown to have good reliability and validity, they are expensive methods to implement and may not be accessible in all populations ${ }^{39}$.

Another method track TL that may be of benefit when training large groups include measuring total running distance, or weight lifted utilizing subjective measures ${ }^{39}$. This method may be particularly useful 167 in military populations upon return from patrol, due to their ability and operational requirement in 168 tracking distances covered. In support of subjective measures, a systematic review on endurance 169 athletes ${ }^{30}$ on endurance runners found a medium effect size $(r=0.59 ; \mathrm{Cl} \text { and } p \text { not reported })^{42}\left(r^{2}=0.36\right.$, $170 \mathrm{Cl}$ and $p=0.001)^{43}$ between subjective reports of high total training distance and rates of injury or pain.

171 Lastly, there are other methods which have been used to track TL, though these are unlikely to be used 172 in tactical populations due to logistical concerns and time constraints ${ }^{39}$. For example, despite time 173 motion analysis being found to be effective in tracking fatigue in professional soccer players ${ }^{44}$, it is 174 unlikely that tactical populations would have the time or resources to record and perform film review of 175 all training and occupational settings. Similarly, despite training diaries being used to track load, concern 176 exists with regards to the accuracy of self-reporting ${ }^{45}$; especially if trying to recall events that occurred 177 at the beginning of long hours of training ${ }^{46}$.

179 Internal Measurements of Training Load

While EL measurements attempt to measure the amount of work done, IL measurements are more 181 focused on the individual's response to the $\mathrm{TL}^{17}$. Numerous methods to track IL including heart rate $182(H R)$, session Rating of Perceived Exertion (sRPE), and questionnaires. Historically heart rate (HR) has 183 been used to track IL due to an almost linear relationship with $\mathrm{VO}_{2 \max }{ }^{47}$. This allows practitioners to 184 quantify how each individual is responding to the imposed work load ${ }^{48}$. Likewise, blood lactate is 
related to $\mathrm{VO}_{2 \mathrm{Max}}$ and may be used to track training load and intensity ${ }^{49}$. As this measure has also been

linked to load carriage performance in soldiers ${ }^{50}$, it may be a useful tool to track intensity and performance. While these methods are accurate, they can be invasive and may require a high level of technical skill or the necessary technology to be performed, and therefore may not be feasible in a tactical population. As an example, while measuring $\mathrm{HR}$ at one set point is a simple task, requiring only a stopwatch, measuring and recording HR consistently over a period time may require more sophisticated technology, such as HR chest straps ${ }^{39}$. Utilizing fitness watches to measure heart rate may be an alternative; however, research has shown that these devices are less accurate at higher heart rates compared to chest straps ${ }^{47}$. Incorporating the Rating of Perceived Exertion (RPE) scale may be useful, as it is both low cost and easy to administer, especially to larger groups ${ }^{48}$.

The RPE scale (Figure 1) was designed by Borg ${ }^{51}$, as an attempt to measure the level of physical strain during activity. It was proposed by Foster et al. ${ }^{52}$, that the this scale can be modified to a $0-10$ scale (Figure 2), and a score given at the end of activity. This score can then be multiplied by the duration of the session for a measure of TL, called session RPE or SRPE ${ }^{52}$. For example, if an athlete completed a 60minute weight lifting session, and reported the session was a 6 on the modified RPE, the athlete would have a SRPE of $360(60 \times 6)$ arbitrary units (AU). Previous research has shown that this method correlates well with blood lactate concentration and heart rate after exercise ${ }^{53,54}$. In a study by Gabbet et al. ${ }^{53}$ the correlations between SRPE and both heart rate and blood lactate concentration were found to be $r=0.89$ and $r=0.86$ respectively, showing a high correlation between measures. These results suggest sRPE, using the modified scale, can be used to accurately measure IL by tactical practitioners after a variety of activities, such as physical training sessions. While tactical personnel do tend to perform physical activity throughout the day, previous research has confined the "session duration" to fixed training hours experienced each day (0600 - 2200), allowing comparison of RPE scores across days ${ }^{55}$. There was good agreement between RPE and recorded training impulse (TRIMP) scores $\left(R^{2}=0.57-0.77\right)$, showing that this 
may be a valid method to compare RPE scores in tactical populations though further research will be

210 necessary ${ }^{55}$

211 Training impulse (TRIMP) was developed by Bannister et al. ${ }^{56}$ as a method of quantifying a training

212 session. This method is calculated by using training duration, maximal heart rate, resting heart rate,

213 average heart rate, and a sex-dependent exponential coefficient ${ }^{56}$. This equation was further modified

214 by Manzi et al. ${ }^{57}$, by introducing an individual based exponential factor. The modification was done in

215 attempts to better determine individual physiological response to exercise ${ }^{57}$. The use of this equation,

216 TRIMP ${ }_{i}$, has been shown to be a valid method to track fitness and performance changes in long distance

217 runners ${ }^{57}$ as well as aerobic fitness in team sport ${ }^{58}$. Another method of calculating TRIMP, Edward's

218 TRIMP, multiples the duration accumulated in five HR zones (zone $1=50-60 \% H R_{\text {Max }}$, zone $2=60-70 \%$,

219 zone $3=70-80 \%$, zone $4=80-90 \%$, and zone $5=90-100 \%$ ) by a coefficient for each zone and then sums

220 the result ${ }^{59}$. This equation was utilized in military training and found agreement $\left(R^{2}=0.34-0.49\right)$

221 between TRIMP and distance, suggesting this may be a valid method to calculate internal load, though it

222 may be limited due to the variable training activities and prolonged time frames found in military

223 populations ${ }^{55}$. Utilizing TRIMP may be an effective means track IL over time in tactical populations,

224 particularly Edward's TRIMP as an individual factor will not need to be calculated and it accounts for

225 activity completed in various HR zones.

226 Heart rate variability (HRV), the beat-to-beat fluctuation of resting HR, is another measure of IL ${ }^{60}$. The 227 autonomic nervous system (ANS) plays a crucial and complex role in maintaining the body's homeostasis $228{ }^{60}$. While the ANS is involved in many different mechanisms, its ability to control HR and role in overuse 229 injuries is a key factor when it comes to monitoring $\mathrm{TL}^{60}$. Examining the physiology of this relationship is 230 beyond the scope of this article, but to paraphrase, using the parasympathetic and sympathetic nervous 231 systems, the ANS is able to increase and decrease $H R$, and release chemical mediators in response to 232 injuries, including overuse injuries ${ }^{61}$. HRV aims to indirectly measure the ANS by analyzing the change in 
time between heart beats during resting $\mathrm{HR}^{60}$. Significant changes from an individual's baseline may show that the ANS is under stress, potentially due to overtraining or the onset of an overuse injury ${ }^{60}$.

Various wellness questionnaires, which examine factors such as sleep quantity and sleep quality, injuries. However, this may be beneficial to those working with tactical populations given the amount of non-physical stress, such as psychological, that are experienced ${ }^{62,63}$. Currently, research is inconclusive about the relationship between HRV and overtraining, with evidence both for and against ${ }^{63-65}$, but this may be a valuable tool to measure the amount of stress, both physical and other, that are being experienced by tactical personnel.

\section{feelings of fatigue and soreness, have also been used in an attempt to measure IL ${ }^{39}$. One such survey,} the Recovery-Stress Questionnaire for Athletes (RSQ), was created to identify the extent of an athlete's physical and mental exhaustion and recoverability ${ }^{66}$. This questionnaire consists of 19 subscales that discuss various topics such as general and emotional stress, burnout, physical complaints and physical recovery among others ${ }^{66}$. The survey is periodically given out, with one study administering the survey four times during a three week period ${ }^{67}$. It has previously been shown to be able to track the general parameters of training stress of athletes across multiple sports ${ }^{66}$, though it is unknown how this scale will apply to those in tactical populations or if they will require a more specific questionnaire for their 254 Another questionnaire that attempts to quantify recovery is the total quality recovery process (TQR) ${ }^{68}$. 255 This process is divided into two parts, the first being a perceived recovery scale (TQR perceived) (Figure 
1). Structured like the Borg RPE Scale, this 6-20 scale attempts to measure an individual's perceived recovery at the end of the day ${ }^{68}$. The second aspect of TQR (TQR action) is a more objective measure of recovery where individuals earn recovery points (20 points maximum) based on nutrition and hydration (10 points maximum), sleep and rest (4 points), and relaxation and emotional support (3 points) (Figure $2603)^{68,69}$. As this method combines both perceived and an objective score for recovery, it may be useful in 261 tactical populations, though future research will be needed to validate this process.

\section{Insert Figure 1 Here}

263 Insert Figure 2 Here

264 Insert Figure 3 Here

266 Lastly, while the above methods may be more complex, previous research in military populations has 267 examined muscle soreness and physical fatigue using $0-10$ scales ${ }^{55}$. While this study, did not examine 268 these measures in relation to injury, these simple questions may be able track how tactical personnel 269 are managing their current $\mathrm{TL}^{55}$. Various questionnaires exist that track both the physical and 270 psychological stress and recovery experienced by individuals ${ }^{66,68}$. Tactical practitioners can utilize these 271 measures periodically to track their personnel. If measures such as these prove to be too time-

272 consuming implementing muscle soreness and physical fatigue scales may be an alternative method to 273 track IL ${ }^{55}$.

274 Insert Table 1 Here

276 Acute:Chronic Workload Ratio

277 Acute:Chronic Workload Ratio (ACWR) is an attempt to provide a more complete picture of an 278 individual's cumulative load by comparing an acute workload to a chronic workload and quantifying the 
changes over time ${ }^{17}$. As mentioned above, it may be the rate of change in load, more than the absolute

load, that relates to injury risk ${ }^{31}$. The importance of rate of change in load can be historically seen through the $10 \%$ rule which states that increases in exercise frequency, duration, or intensity should be limited to $10 \%$ of the previous week ${ }^{70}$. While the timeframes may vary, in sports the acute workload is typically represented by one week, while the chronic load is a summation of the previous 3-6 weeks ${ }^{17}$. If the acute workload is greater than the chronic workload (signifying increases in training load), the ratio will be greater than one, and the individual will be in a fatigued state ${ }^{17}$. Conversely, if the acute workload is less than chronic workload, the ratio will less than one, and injury may be less likely however performance may plateau or decline with inadequate stimulus ${ }^{17}$. The chronic workload has also been called 'fitness' in the literature, while the acute workload has been called 'fatigue' ${ }^{17}$. Evidence shows that high chronic workload or 'fitness', may protect against spikes in acute workload or 'fatigue' 17,71,72. In a study by Malone et al., it was found that a high chronic TL (4750 AU) measured by sRPE protected against injury from maximal velocity running ${ }^{71}$. In another study by Hulin et al. ${ }^{72}$, it was found that a high chronic workload (>16095 meters covered) combined with a moderate ACWR (1.03-1.38; Relative Risk $(R R)=6.2 \pm 2.2$ ) resulted in a lower injury risk than low chronic workload $(<16095$ meters covered) combined with a moderate ACWR (1.03-1.38; RR=9.3 \pm 2.2$)$. RR states how many times more likely an outcome will occur in an exposed group compared to a non-exposure group ${ }^{73}$. In the case of the Hulin et al. article ${ }^{72}$, those who experienced a high chronic workload were 6.2 times more likely to experience an injury, while those in the low chronic workload were 9.3 times more likely to experience an injury. ACWR may be more appropriate to utilize than the $10 \%$ rule, as it is not a rigid law, but can be adjusted based on past training.

One limitation of the ACWR model is that it does not account for the decaying effects of fatigue and fitness over time, and therefore may be able to be improved ${ }^{39,74}$. A new method utilizing exponential weighted moving averages (EWMA), instead of rolling averages, was recently put forward by Williams et 
$\mathrm{al}^{75}$. This method attempts to account for the decaying effects by assigning a decreasing weighting for older values ${ }^{75}$. A study by Murray et al. ${ }^{74}$ compared EWMA ACWR to rolling average ACWR and found that, while both models showed a significant increase in injury risk with high ACWR, EWMA was more sensitive to detect increases in injury likelihood at higher ACWRs. When compared with an ACWR of 1.01.49, a rolling average ACWR of 2.0 was shown to have a relative injury risk of 6.52 [4.83-8.80], a statistically significant finding. Utilizing the same comparison, but with EWMA, the relative risk increased to 21.28 [20.02-22.62] - demonstrating a much higher relative injury risk. Incorporating an EWMA ACWR over a rolling average ACWR may be a more sensitive and advantageous method ${ }^{75}$.

Clinicians and practitioners can utilize ACWR with any of the above-mentioned variables. By

incorporating ACWR with measures such as a total distance, SRPE, or volume load, practitioners may be better able to predict how well their personnel will respond to future programs. If knowing that over the last 3 weeks, personnel have only covered an average of $2000 \mathrm{~m}$ per week, practitioners can calculate that covering $4000 \mathrm{~m}$ will result in an ACWR of 2.00 and therefore increase injury risk (acute load divided by chronic load, or $4000 \mathrm{~m}$ divided by $2000 \mathrm{~m}$ ). Practitioners can adjust their scheduled training sessions either based off previous work load or off current occupational demands (e.g. dismounted patrols) to keep personnel within a safe range.

While ACWR may be a useful tool for predicting injury risk, there are potential limitations affecting its validity. One such issue is the potential spurious correlations that may exist between ACWR and injury risk $^{76}$. This is likely due to the fact that the acute load is used in the calculation of the chronic load, as the acute load is on both sides of the equation ${ }^{76}$. A second impacting factor is the confounding effect training schedule has on the ability of ACWR to predict injury risk ${ }^{77}$. This was calculated with regards to sporting teams, so it remains to be seen if this relationship exists in tactical population. However, though ACWR may be an effective method to calculate injury risk, it should not be solely relied upon by clinicians and practitioners. 
Research has hypothesized that musculoskeletal injuries may be linked to adverse responses in $\mathrm{TL}^{60}$, while specifically researched targets regarding TL and injury in the athletic domain have been studied. Research has shown that two week cumulative sRPE loads $>3700 \mathrm{AU}{ }^{78}$, and high three week running distances (73721 - 86662 meters) ${ }^{36}$ are likely to increase injury risk in Australian Rules football players while studies across multiple sports have shown that ACWR ratios ranging from $0.8-1.3$ may minimize injury risk while ensuring increases in fitness ${ }^{35,72}$. Utilizing either cumulative loads or ACWR provides information to medical staff and strength and conditioning (S\&C) coaches which may assist with reducing injury risk and maximizing performance in tactical environments. It is unlikely that these numbers will be directly transferable given the differences that exist between the tactical and athletic domain, though it should be noted that members of tactical population regularly play sport ${ }^{79,80}$.

The Associations of Training Load and Fitness and Performance

While TL may assist with mitigating injury risk, it also is related to fitness and performance. Fitness is a key requirement for tactical personnel and is associated with successful occupational task performance ${ }^{2}$, reduced injury risk, ${ }^{81}$ and mental health benefits ${ }^{16}$. However, while training to increase fitness is needed, it may pose a risk if not monitored correctly, as supported by findings that in military personnel, physical training and sports participation are leading causes of injuries ${ }^{15}$. Tracking TL may be able to ensure that tactical populations are training at a high enough intensity to increase fitness while not unnecessarily increasing risk of injury ${ }^{17}$. In AFL players, it was found that those who had completed high TL (1600-2000 AU per week) increased their $2 \mathrm{~km}$ time trial compared to those who completed very high (>2000 AU per week), moderate (1250-1599 AU per week), and low (<1250 AU per week) TL as measured by SRPE ${ }^{78}$. In a study by Gabbett et al. ${ }^{53}$, it was found that while increases in TL of 175 to 620 
$A U$, as measured by SRPE, did not result in any increase risk of injury, it did result in decreased performances in agility. These results provide evidence that tracking TL cannot only influence injury risk, but fitness and performance as well. Given the inherent dangers tactical populations can encounter ${ }^{7,82}$, decreases in performance or losses of fitness do not simply result in a lost game, but can have life and death consequences. By implementing a method of monitoring TL tactical populations can aim for, and train at a level that maximizes performance gains while minimizing injury risk ${ }^{39,83}$.

While there are notable differences between tactical populations and elite athletes, the TL methodology used in elite sport may provide a template for tactical personnel. Preliminary studies in military populations show the associated increase in injury risk with increase in physical activity ${ }^{26,28}$. While these studies have shown the potential harmful impacts of excessive physical activity, modern methods such as SRPE, ACWR or any of the other various methods to track EL and IL used in elite sports ${ }^{39}$, appear to be suitable to implement to track and adjust $\mathrm{TL}^{17}$.

Practitioners must recognize that excessive TL is just one potential causative factor of injury in tactical populations. While there are various other causative factors, i.e. smoking ${ }^{27,81}$, previous injury ${ }^{26,27}$, and poor fitness ${ }^{81}$, little research has been performed regarding monitoring TL, especially using the methods seen in elite sport ${ }^{17,39}$. The current depth of research is lacking given the impact overloading or underloading has on injuries in tactical populations. Multiple studies have shown the impact of high physical activity and repetitive microtrauma has on musculoskeletal injuries in tactical populations ${ }^{28,84}$. A large amount of these injuries are due to repetitive microtrauma, or overuse, accounting for almost 4 times as many injuries as acute trauma ${ }^{84}$. Military recruits especially are at risk for injury due to sudden and large increases in TL due to high amounts of running and other physical activity with possibly little to no prior training ${ }^{85,86}$. Given the impact injuries have on both institutional costs, approximately $\$ 1.5$ billion (USD) per year in United States Army ${ }^{22,23}$, and organizational workload, it is vital that tactical populations begin to research and implement these practices. 


\section{Conclusion}

Given both the high physical workload and injury rate within tactical populations, it is important that steps are put in to place to maximize performance in decrease injury risk. A wide range of variables including HR, SRPE, HRV, distance covered, volume-load among others may allow practitioners to monitor TL within their personnel. In addition, ACWRs could be devised to minimize any spikes in training load which may increase injury risk. A comprehensive understanding of TL may allow for optimizing the programming of activities such as pack marches and patrols, to allow for the addition of, or reduction of training where required. For example, if a military unit is planning to complete a $5 \mathrm{~km}$ dismounted patrol in 4 weeks, a S\&C coach can analyze the distance covered previously during field and physical training sessions. Due to the minimal research performed within the tactical domain to date, specific ratios are not currently available, however evidence from elite sport highlights that ACWRs from 0.8-1.3 may be optimal for both performance gains and injury reduction.

Figure 1. Borg RPE Scale and Total Quality Recovery Scale. Reproduced from Kentta and Hassmen (48)

Figure 2. Modified Borg RPE Scale. Reproduced from Foster et al. (25)

Figure 3. TQR Action Scoring Guide. Reproduced from Kentta and Hassmen (49)

\section{References}

1. Dawes JJ, Orr RM, Flores RR, Lockie RG, Kornhauser C, Holmes R. A physical fitness profile of state highway patrol officers by gender and age. Ann Occup Environ Med. 2017;29.

2. Robinson J, Roberts A, Irving S, Orr R. Aerobic fitness is of greater importance than strength and power in the load carriage performance of specialist police. Int J Exerc Sci. 2018;11(4):987-998.

3. Carlton A, Gorey R, Orr R. The Impact of Suppressing a Structural Fire on Firefighter Hydration. J Aust Strength Cond. 2016;24(5):27-33. 
4. Orr R, Pope R, Coyle J, Johnston V. Occupational loads carried by Australian soldiers on military operations. J Health Saf Environ. 2015;31(1):451-467.

5. Divencenzo HR, Morgan AL, Laurent CM, Keylock KT. Metabolic demands of law enforcement personal protective equipment during exercise tasks. Ergonomics. 2014;57(11):1-6.

6. Knapik JJ, Reynolds KL, Harman E. Soldier load carriage: historical, physiological, biomechanical, and medical aspects. Mil Med. 2004;169(1):45.

7. Pryor RR, Colburn D, Crill MT, Hostler DP, Suyama J. Fitness characteristics of a suburban special weapons and tactics team. J Strength Cond Res. 2012;26(3):752.

8. Hunt AP, Orr RM, Billing DC. Developing physical capability standards that are predictive of success on Special Forces selection courses. Mil Med. 2013;178(6):619.

9. Carbone PD, Carlton SD, Stierli M, Orr R. The impact of load carriage on the marksmanship of the tactical police officer: a pilot study. J Aust Strength Cond. 2014;22(2):50-57.

10. Keeler JM. The Effect of Tactical Tasks and Gear on Muscle Activation of SWAT Officers [Master of Science]: Theses and Dissertations--Kinesiology and Health Promotion, University of Kentucky; 2014.

11. Drain J, Orr R, Attwells R, Billing D. Load Carriage Capacity of the Dismounted Combatant-A Commanders' Guide. Defence Science and Technology Organisation Victoria (Australia) Human Protection and Performance Div;2012.

12. Rossi R. Fire fighting and its influence on the body. Ergonomics. 2003;46(10):1017-1033.

13. Orr R, Pope R, Johnston V, Coyle J. Soldier load carriage: An investigation into the load carriage conditioning practices of the Australian Regular Army. Paper presented at: Australian Military Medicine Association2012.

14. Brandl SG, Stroshine MS. The Physical Hazards of Police Work Revisited. Police Q. 2012;15(3):262-282.

15. Jones B, Knapik J. Physical Training and Exercise-Related Injuries. Sports Med. 1999;27(2):111125.

16. Crowley SK, Wilkinson LL, Wigfall LT, et al. Physical fitness and depressive symptoms during army basic combat training. Med Sci Sports Exerc. 2015;47(1):151-158.

17. Gabbett TJ. The training-injury prevention paradox: should athletes be training smarter and harder? Br J Sports Med. 2016;50(5).

18. Lyons K, Radburn C, Orr R, Pope R. A profile of injuries sustained by Law Enforcement Officers: A Critical Review. Int J Environ Res Public Health. 2017.

19. Taylor NA, Dodd MJ, Taylor EA, Donohoe AM. A retrospective evaluation of injuries to Australian urban firefighters (2003 to 2012): injury types, locations, and causal mechanisms. J Occup Environ Med. 2015;57(7):757-764.

20. Pope R, Orr R, MacDonald D. Incidence rates of reported work health and safety incidents and injuries in part-time and full-time Australian Army personnel. J Mil Veterans Health. 2015;23(4):45-46.

21. Kaufman KR, Brodine S, Shaffer R. Military training- related injuries: Surveillance, research, and prevention. Am J Prev Med. 2000;18(3):54-63.

22. Hilyer JC, Brown KC, Sirles AT, Peoples L. A flexibility intervention to reduce the incidence and severity of joint injuries among municipal firefighters. J Occup Med. 1990;32(7):631-637.

23. Nindl BC, Williams TJ, Deuster PA, Butler NL, Jones BH. Strategies for optimizing military physical readiness and preventing musculoskeletal injuries in the 21st century. US Army Med Dep J. 2013:5-23.

24. Lisman P, Connor FG, Deuster PA, Knapik JJ. Functional movement screen and aerobic fitness predict injuries in military training. Med Sci Sports Exerc. 2013;45(4):636. 
25. Robinson $\mathrm{M}$, Siddall A, Bilzon J, et al. Low fitness, low body mass and prior injury predict injury risk during military recruit training: a prospective cohort study in the British Army. BMJ Open Sport Exerc Med. 2016;2(1).

26. Almeida SA, Williams KM, Shaffer RA, Brodine SK. Epidemiological patterns of musculoskeletal injuries and physical training. Med Sci Sports Exerc. 1999;31(8):1176.

27. Bulzacchelli MT, Sulsky SI, Rodriguez-Monguio R, Karlsson LH, Hill MOT. Injury During U.S. Army Basic Combat Training: A Systematic Review of Risk Factor Studies. Am J Prev Med. 2014;47(6):813-822.

28. Trank TV, Ryman DH, Minagawa RY, Trone DW, Shaffer RA. Running mileage, movement mileage, and fitness in male US Navy recruits. Med Sci Sports Exerc. 2001;33(6):1033-1038.

29. Eckard TG, Padua DA, Hearn DW, Pexa BS, Frank BS. The relationship between training load and injury in athletes: a systematic review. Sports Med. 2018;48(8):1-33.

30. Johnston R, Cahalan R, O'keeffe M, O'sullivan K, Comyns T. The associations between training load and baseline characteristics on musculoskeletal injury and pain in endurance sport populations: A systematic review. J Sci Med Sport. 2018(9):910-918.

31. Soligard T, Schwellnus M, Alonso J-M, et al. How much is too much? (Part 1) International Olympic Committee consensus statement on load in sport and risk of injury. Br J Sports Med. 2016;50(17):1030-1041.

32. Halson S. Monitoring Training Load to Understand Fatigue in Athletes. Sports Med. 2014;44(Supplement 2):139-147.

33. Piggott B. The relationship between training load and incidence of injury and illness over a preseason at an Australian Football League Club: Faculty of Computing, Health and Science, Edith Cowan University; 2008.

34. Cummins C, Orr R, O'Connor H, West C. Global positioning systems (GPS) and microtechnology sensors in team sports: a systematic review. Sports Med. 2013;43(10):1025-1042.

35. Ehrmann FE, Duncan CS, Sindhusake D, Franzsen WN, Greene DA. GPS and Injury Prevention in Professional Soccer. J Strength Cond Res. 2016;30(2):360-367.

36. Colby MJ, Dawson B, Heasman J, Rogalski B, Gabbett TJ. Accelerometer and GPS-derived running loads and injury risk in elite Australian footballers. J Strength Cond Res. 2014;28(8):2244-2252.

37. Johnston RJ, Watsford ML, Kelly SJ, Pine MJ, Spurrs RW. Validity and interunit reliability of $10 \mathrm{~Hz}$ and $15 \mathrm{~Hz}$ GPS units for assessing athlete movement demands. J Strength Cond Res. 2014;28(6):1649-1655.

38. Veenstra BJ, Wyss T, Roos L, Delves SK, Buller M, Beeler N. An evaluation of measurement systems estimating gait speed during a loaded military march over graded terrain. Gait Posture. 2018;61:204-209.

39. Bourdon PC, Cardinale M, Murray A, et al. Monitoring athlete training loads: consensus statement. Int J Sports Physiol Perform. 2017;12(Suppl 2):S2-161-S162-170.

40. Benson AC, Bruce L, Gordon BA. Reliability and validity of a GPS-enabled iPhone TM "app" to measure physical activity. J Sports Sci. 2014;33(14):1-8.

41. Haff GG, Triplett NT. Essentials of Strength Training and Conditioning. 4th ed: Human Kinetics; 2015.

42. Lysholm J, Wiklander J. Injuries in runners. Am J Sports Med. 1987;15(2):168-171.

43. Bovens A, Janssen $G$, Vermeer H, Hoeberigs J, Janssen M, Verstappen F. Occurence of Running Injuries in Adults Following a Supervised-Training Program. Int J Sports Med. 1989;10:S186-S190.

44. Mohr M, Krustrup P, Bangsbo J. Match performance of high-standard soccer players with special reference to development of fatigue. J Sports Sci. 2003;21(7):519-528.

45. Sallis JF, Saelens BE. Assessment of Physical Activity by Self-Report: Status, Limitations, and Future Directions. Res Q Exerc Sport. 2000;71(2):1-14. 
46. Hoyt RW, Opstad PK, Haugen A-H, DeLany JP, Cymerman A, Friedl KE. Negative energy balance in male and female rangers: effects of $7 \mathrm{~d}$ of sustained exercise and food deprivation-. Am J Clin Nutr. 2006;83(5):1068-1075.

47. Strath SJ, Swartz AM, Bassett DR, O'Brien WL, King GA, Ainsworth BE. Evaluation of heart rate as a method for assessing moderate intensity physical activity. Med Sci Sports Exerc. 2000;32(9 Suppl):S465.

48. Impellizzeri FM, Rampinini E, Coutts AJ, Sassi A, Marcora SM. Use of RPE-based training load in soccer. Med Sci Sports Exerc. 2004;36(6):1042-1047.

49. Farrell PA, Wilmore J, Coyle E, Billing J, Costill DL. Plasma Lactate Accumulation and Distance Running Performance. Med Sci Sports Exerc. 1993;25(10):1091-1097.

50. Simpson RJ, Graham SM, Connaboy C, Clement R, Pollonini L, Florida-James GD. Blood lactate thresholds and walking/running economy are determinants of backpack-running performance in trained soldiers. Appl Ergon. 2017;58:566-572.

51. Borg G. Perceived exertion as an indicator of somatic stress. Scand J Rehabil Med. 1970;2(2):92.

52. Foster $\mathrm{C}$, Florhaug JA, Franklin J, et al. A new approach to monitoring exercise training. J Strength Cond Res. 2001;15(1):109-115.

53. Gabbett TJ, Domrow N. Relationships between training load, injury, and fitness in sub-elite collision sport athletes. J Sports Sci. 2007;25(13):1507-1519.

54. Scott TJ, Black CR, Quinn J, Coutts AJ. Validity and reliability of the session-RPE method for quantifying training in Australian football: a comparison of the CR10 and CR100 scales. J Strength Cond Res. 2013;27(1):270-276.

55. O'Leary TJ, Saunders SC, McGuire SJ, Venables MC, Izard RM. Sex Differences in Training Loads during British Army Basic Training. Med Sci Sports Exerc. 2018.

56. Bannister E. Modeling elite athletic performance. Champaign, IL: Human Kinetics.

57. Manzi V, lellamo F, Impellizzeri F, D'Ottavio S, Castagna C. Relation between individualized training impulses and performance in distance runners. Med Sci Sports Exerc. 2009;41(11):2090.

58. Malone S, Collins K. Relationship Between Individualized Training Impulse and Aerobic Fitness Measures in Hurling Players Across a Training Period. J Strength Cond Res. 2016;30(11):3140.

59. Edwards S. High performance training and racing. In: The Heart Rate Monitor Book. Sacramento: Fleeet Feet Press; 1994:113-123.

60. Gisselman AS, Baxter GD, Wright A, Hegedus E, Tumilty S. Musculoskeletal overuse injuries and heart rate variability: Is there a link? Med Hypotheses. 2016;87:1-7.

61. Hamill RW, Shapiro RE, Vizzard MA. Chapter 4 - Peripheral Autonomic Nervous System. In: Robertson D, Biaggioni I, Burnstock G, Low PA, Paton JFR, eds. Primer on the Autonomic Nervous System (Third Edition). San Diego: Academic Press; 2012:17-26.

62. Ogle AD, Young JA. USAF Special Tactics Operator Combat Exposure and Psychological Stress. Mil Psychol. 2016;28(3):123-133.

63. Mourot L, Bouhaddi M, Perrey S, et al. Decrease in heart rate variability with overtraining: assessment by the Poincaré plot analysis. Clin Physiol Funct Imaging. 2004;24(1):10-18.

64. Le Meur Y, Pichon A, Schaal K, et al. Evidence of parasympathetic hyperactivity in functionally overreached athletes. Med Sci Sports Exerc. 2013;45(11):2061.

65. Hedelin R, Wiklund U, Bjerle P, Henriksson-Larsén K. Cardiac autonomic imbalance in an overtrained athlete. Med Sci Sports Exerc. 2000;32(9):1531-1533.

66. Davis $\mathrm{H}$, Orzeck T, Keelan P. Psychometric item evaluations of the Recovery-Stress Questionnaire for athletes. Psychol Sport Exerc. 2007;8(6):917-938.

67. Kellmann M, GÜnther K-d. Changes in stress and recovery in elite rowers during preparation for the Olympic Games. Med Sci Sports Exerc. 2000;32(3):676-683. 
68. Kenttä G, Hassmén P. Overtraining and recovery. A conceptual model. Sports Med. 1998;26(1):116.

69. Kenttä G, Hassmén P. Train smart: Avoid Overtraining Syndrome. SISU Idrottsbocker; 1999; Stockholm.

70. Sheppard MJ, Triplett NT. Essentials of Strength Training and Conditioning. Fourth edition ed. Champaign, IL: Human Kinetics; 2016.

71. Malone S, Roe M, Doran DA, Gabbett TJ, Collins K. High chronic training loads and exposure to bouts of maximal velocity running reduce injury risk in elite Gaelic football. J Sci Med Sport. 2017;20(3):250-254.

72. Hulin BT, Gabbett TJ, Lawson DW, Caputi P, Sampson JA. The acute: chronic workload ratio predicts injury: high chronic workload may decrease injury risk in elite rugby league players. $\mathrm{Br} \mathrm{J}$ Sports Med. 2015(50):231-236.

73. Viera AJ. Odds ratios and risk ratios: what's the difference and why does it matter? South Med J. 2008;101(7):730.

74. Murray NB, Gabbett TJ, Townshend AD, Blanch P. Calculating acute: chronic workload ratios using exponentially weighted moving averages provides a more sensitive indicator of injury likelihood than rolling averages. Br J Sports Med. 2016.

75. Williams S, West $S$, Cross MJ, Stokes KA. Better way to determine the acute:chronic workload ratio? Br J Sports Med. 2017;51(3):209-210.

76. Lolli L, Batterham AM, Hawkins R, et al. Mathematical coupling causes spurious correlation within the conventional acute-to-chronic workload ratio calculations. Br J Sports Med. 2017.

77. Bornn L, Ward P, Norman D. Training Schedule Confounds the Relationship between Acute:Chronic Workload Ratio and Injury. MIT Sloan Sports Analystics Conference; 2019; Boston, MA.

78. Harrison PW, Johnston RD. Relationship Between Training Load, Fitness, and Injury Over an Australian Rules Football Preseason. J Strength Cond Res. 2017;31(10):2686-2693.

79. Strowbridge N, Burgess K. Sports And Training Injuries In British Soldiers: The Colchester Garrison Sports Injury And Rehabilitation Centre. J R Army Med Corps. 2002;148(3):236.

80. Adams MS, Croft A. Sports Injuries in British Troops deployed on Operation Resolute (Bosnia). J R Army Med Corps. 1997;143(1):35.

81. Knapik JJ, Sharp MA, Canham-Chervak M, Hauret K, Patton JF, Jones BH. Risk factors for trainingrelated injuries among men and women in basic combat training. Med Sci Sports Exerc. 2001;33(6):946.

82. Galdorisi G. The 2016 Australian Defence white paper: A view from across the pacific. AsiaPacific Defence Reporter (2002). 2016;42(5):34-38.

83. Morton RH. Modeling training and overtraining. J Sports Sci. 1997;15(3):335.

84. Hauschild V, Hauret K, Richardson M, Jones BH, Lee T. A Taxonomy of Injuries for Public Health Monitoring and Reporting. Army Public Health Center Aberdeen Proving Ground United States;2017.

85. Orr R, Ford K, Stierli M. Implementaion of an Ability-Based Training Program in Police Force Recruits. J Strength Cond Res. 2016;30(10):2781-2787.

86. Sherrard J, Lenné M, Cassell E, Stokes M, Ozanne-Smith J. Injury prevention during physical activity in the Australian Defence Force. J Sci Med Sport. 2004;7(1):106-117. 


\begin{tabular}{|c|c|}
\hline $\begin{array}{l}\text { Ratings of perceived } \\
\text { exertion (RPE) }\end{array}$ & Total quality recovery (TQR) \\
\hline 6 & 6 \\
\hline 7 Very, very light & 7 Very, very poor recovery \\
\hline 8 & 8 \\
\hline 9 Very light & 9 Very poor recovery \\
\hline 10 & ${ }^{-10}$ \\
\hline 11 Fairly light & 11 Poor recovery \\
\hline 12 & ${ }^{-12}$ \\
\hline 13 Somewhat hard & 13 Reasonable recovery \\
\hline 14 & 14 \\
\hline 15 Hard & 15 Good recovery \\
\hline 16 & 16 \\
\hline 17 Very hard & 17 Very good recovery \\
\hline 18 & 18 \\
\hline 19 Very, very hard & 19 Very, very good recovery \\
\hline $20^{\circ}$ & 20 \\
\hline
\end{tabular}




$\begin{array}{cl}\text { Rating } & \text { Descriptor } \\ 0 & \text { Rest } \\ 1 & \text { Very, Very Easy } \\ 2 & \text { Easy } \\ 3 & \text { Moderate } \\ 4 & \text { Somewhat Hard } \\ 5 & \text { Hard } \\ 6 & \text {. } \\ 7 & \text { Very Hard } \\ 8 & \text {. } \\ 9 & \text { Maximal } \\ 10 & \end{array}$




\section{Recovery Scoring Guide}

Athletes can fill out this guide over the course of a week to assess their own recovery behaviors. Once they have scored a full day, the total reveals whether they are paying adequate attention to their physical and mental recovery needs. 17-20 daily points is optmal; 15-16 points is good but shows room for improvement; 14 or fewer points means the athlete needs a serious individual evaluation of recovery behavioss.

\begin{tabular}{|l|l|l|l|l|l|l|l|l|}
\hline & $\begin{array}{l}\text { Possible } \\
\text { Points }\end{array}$ & Sun. & Mon. & Tues. & Wed. & Thurs. & Fri. & Sat. \\
\hline Nutrition & 8 & & & & & & & \\
\hline Breakfast & 1 & & & & & & & \\
\hline Lunch & 2 & & & & & & & \\
\hline Dinner & 2 & & & & & & & \\
\hline Pre-workout snack & 1 & & & & & & & \\
\hline $\begin{array}{l}\text { Post-exercise carb refueling within } 60 \text { minutes. } \\
\text { (recommended: } 1.0 \text { to } 1.5 \text { g per kilogram of body } \\
\text { weight) }\end{array}$ & 2 & & & & & & & \\
\hline Hydration & & & & & & & & \\
\hline Pre-exercise urine: clear or light color & 2 & & & & & & & \\
\hline Post-exercise urine: clear or light color & 1 & & & & & & & \\
\hline Sleep and Rest & 1 & & & & & & & \\
\hline 8 hours of restful sleep & 4 & & & & & & & \\
\hline Nap during the day & 3 & & & & & & & \\
\hline Relaxation and Emotional Status & 1 & & & & & & & \\
\hline Fully relaxed 60 minutes post-workout of \\
30 minutes of feet-up relaxation post workout
\end{tabular}

\section{SCORING GUIDE ADJUSTMENTS}

Give $1 / 2$ a point for a less than full

breakfast

Give one point for a less than full hench

Give one point for a less than full dinner

Give one point for refueling below the recommended amount or for delaying more than 60 minutes.

Give two points fot 7 to $<8$ hours

Give one point for 6-7 hours

\section{Give one point for mild stress}

Give one point for partial cooldown

\begin{tabular}{|l|}
\hline \\
\hline \\
\hline \\
\hline
\end{tabular}

